\title{
Profile of unaccompanied, unconscious patients in the emergency department
}

\author{
D. P. Singh, ${ }^{1}$ R. P. Acharya, ${ }^{2}$ S. Singh ${ }^{3}$ \\ ${ }^{1}$ Bir Hospital, National Academy of Medical Sciences, Kathmandu; ${ }^{2}$ Tribhuvan University Teaching Hospital, Institute of \\ Medicine, Kathmandu; ${ }^{3}$ KIST Medical College, Kathmandu, Nepal
}

Correspondence to: D. P. Singh, Bir Hospital, National Academy of Medical Sciences, Kathmandu

Email: drdhruwaprasadsingh@gmail.com

\begin{abstract}
Introduction: The burden of unknown and unconscious patient is a common challenge to provide medical care in the emergency department of the hospitals. As the social security systems like insurance does not exist and poverty is rampant, it will continue in the future too. In this context this study is an attempt to analyze the morbidity \& mortality as well as the types of illness, causes of unconsciousness and the source of unconsciousness in these patients without any identity.

Methods: A retrospective analysis of the unaccompanied, unconscious patients attending the emergency department of Bir hospital during the Nepali year 2066 Bikram Sambat (14 April 2009 to 13 April 2010) was carried out.

Results: Two-thirds of these patients were brought to hospital by the police. The next category $(20 \%)$ were brought by unknown person and left without any information.

Conclusions: Use of the type of substance and their nature remains unclear and there is a need to develop a trend to identify these substances so that specific treatment and hence preventive measures can be implemented effectively.
\end{abstract}

Keywords: Destitute, unconscious, unknown substance

\section{Introduction}

The burden of unknown and unconscious patient is a common challenge to provide the medical care in the emergency department of Bir Hospital. As many hospitals and medical institutions are hostile to accept patients without capacity to pay, most of the patients are either directly brought or referred to Bir Hospital. Throughout the world, emergency department of the hospitals face the challenge to take care of the destitute. ${ }^{1}$ Obviously, the society tends to value the productive population and the destitute do not receive preference in care. ${ }^{2}$ Thus, it has lots of problems \& constraints to sort out and to provide the medical care. Such an 'acute confusional state' is difficult to be defined and as such needs further study. ${ }^{3}$ The coma mnemonic, AEIOU TIPS, (alcohol, epilepsy, insulin, overdose, uremia, trauma, infection, psychiatric, stroke) provides an excellent memory tool for the evaluation of decreased level of consciousness in the emergency setting. ${ }^{4}$

This study has been aimed to analyze the morbidity \& mortality as well the types of illness, causes of unconsciousness and the source of unconscious, unknown patient. Even though this is a day to day problem, there has been hardly any study in Nepal in this field.

\section{Methods}

A retrospective analysis of the unaccompanied, unconscious patients attending the emergency department of Bir hospital during the Nepali year 2066 Bikram Sambat (14 April 2009 to 13 April 2010) was carried out. Only unconscious patients who were not accompanied by their 
Unaccompanied, unconscious patients in the emergency department

relatives, friends or neighbours were included in the study. Demographic data, clinical presentation and laboratory reports were analysed to find out the age and sex distribution; who brought them to the hospital; common causes of unconsciousness in those patients and mortality.

\section{Results}

\section{Demography:}

In the span of one year, a total of 64,240 patients received care in the emergency department of Bir Hospital and out of them, 248(0.4\%) were unaccompanied unconscious patients. The age-wise distribution of cases is shown in table 1.

Table 1: Age-wise distribution

$\begin{array}{ll}\text { Age (years) } & \text { Number }(\%) \\ <20 & 7(2.8) \\ 21-30 & 28(11.3) \\ 31-40 & 45(18.1) \\ 41-50 & 51(20.6) \\ 51-60 & 46(18.6) \\ 61-70 & 38(15.3) \\ 71 \text { and above } & 33(13.3) \\ \text { Total } & \mathbf{2 4 8 ( 1 0 0 )}\end{array}$

Male is to female ratio was $2.4: 1$.

\section{Who brought them to the hospital?}

About sixty-seven percent of these patients were brought by police from Kathmandu valley. Usually, the police brought them when they were found unconscious in the street. Similarly, 32(12.9\%) cases were brought by the passersby and were left at the emergency. Additional 19.8\% of patients were brought by unknown persons and were left in the emergency without any information.

\section{Common causes}

Alcohol intoxication was found in 54(21.8\%) cases and out of them $45(18.1 \%)$ had hypoglycaemia. Among alcohol intoxication patients, $20(8.1 \%)$ had physical assaults and/ or road traffic accidents.

Another major group (13\%) comprises of the street beggars with poor hygiene and suffering from acute exacerbation or superadded infections on chronic infections.

Third major group (12.1\%) of unconscious patients was ingestion of unknown substances. Upon presentation, clinically the patients were intoxicated with some drugs but recover gradually. Probably depending on the dose ingested, the level of consciousness varies. Fortunately, the recovery in those patients was $100 \%$. After recovery, the typical history reveals loss of consciousness after intake of common cold drinks like Fruity, Fanta, and Coke offered by unknown persons and they lost money, golden ornaments etc. Regular laboratory tests are within normal limits. However, gastric contents of these patients were not analysed. The common places of such incidents are bank areas, temples and monasteries.

Less frequent causes in these cases were psychosis (5.2\%), epilepsy $(2.8 \%)$, head injury $(2.4 \%)$, poly trauma $(2.0 \%)$ and stroke $(1.6 \%)$.

\section{Mortality}

Ten $(4.0 \%)$ of them were already dead before arriving emergency department (commonly, labeled as 'brought dead'). Mortality in the hospital was 39(15.7\%); 10.9\% died within 24 hours and the remaining $4.8 \%$ died after 24 hours in the hospital.

\section{Discussion}

Unaccompanied, unconscious patients in the emergency department are predominantly males $(\mathrm{M}: \mathrm{F}=2.4: 1)$. In this study, the most common age group affected was 41 to 50 years but interestingly, all age groups above the age of 21 have more than $10 \%$ in each age group. A study on destitute attending emergency department in France had an average age of 35 years. $^{1}$

Two-thirds of these patients were brought to the hospital by police as they found unconscious people lying on road side. In $19.8 \%$ of patients, it was not possible to identify who brought them to the emergency department. It is assumed that most of the times they are brought by unrelated people who prefer to run away without identification so that they can escape from interrogation by medical staff or police and the treatment cost. Sometimes they may even be family members who are exhausted for taking care or spending for the medical cost.

In this study, alcohol intoxication is the commonest cause $(21.8 \%)$ of unaccompanied unconscious presentation to the emergency department. Excess alcohol consumption and associated harms in terms of health, crime and disorder have been highlighted by the government and media, causing considerable public concern. ${ }^{5}$ No specific anti-dote is available for the treatment of alcohol intoxication. ${ }^{6}$ Beggars are another group of such case load in the emergency department of Bir Hospital. They usually present with infection and with poor hygiene. At times, drug intoxications may mask (other) life-threatening conditions. ${ }^{7}$

The commonly presenting cases with ingestion of unknown substance given by strangers are relatively stable but there 
is a need of toxicology laboratory so that identification of the substance is possible and then specific treatment and the preventive measures can be implemented effectively. ${ }^{8}$

Similar to other studies stroke was relatively rare cause of altered consciousness. ${ }^{9}$

Regarding mortality, in this study $4 \%$ were already dead upon arrival to the emergency department and an additional $15.7 \%$ died at hospital. A study done on patients presenting to emergency with collapse published back in 1994 from United Kingdom showed the mortality as high as $31.3 \%{ }^{10}$ This may be due to the variation in the definition of the cases. In the later study, all the cases of 'collapse' were included. A recently published study from Sweden done among coma and impaired consciousness in the emergency room revealed favourable prognosis among poisoned patients but poor in the rest of the study population as a group. ${ }^{11}$

\section{Conclusions}

Unaccompanied, unconscious patients are priority patients for emergency medical service. Alcohol intoxication, infections in beggars and ingestion of unknown substance are major causes and quite a big amount of resources has been utilized for them.

It is more social or administrative problem than the medical problem. There is a need of toxicology laboratory is order to identify and properly provide medical care.

\section{References}

1. Brücker G, Nguyen DT, Lebas J. Access to health care for destitute persons at Public Assistance Hospitals in Paris. Bull Acad Natl Med 1997 Nov;181(8):1681-97.

2. Fortes PA, Zoboli EL. A study on the ethics of microallocation of scarce resources in health care. $\mathrm{J}$ Med Ethics 2002 Aug;28(4):266-9.

3. Foreman MD. The cognitive and behavioral nature of acute confusional states. Sch Inq Nurs Pract. 1991;5(1):3-16.

4. Hartzell CW. Sleeping beauty: a case of pickwickian syndrome. J Emerg Nurs. 1989 Jan-Feb;15(1):8-11.

5. Benger J, Carter R. Could inter-agency working reduce emergency department attendances due to alcohol consumption? Emerg Med J. 2008 Jun;25(6):331-4.
6. Marco CA, Kelen GD. Acute intoxication. Emerg Med Clin NorthAm. 1990 Nov;8(4):731-48.

7. Kinn M, Holzbach R, Pajonk FG. Substance-abuse related emergencies-illegal drugs, part II. Anasthesiol Intensivmed Notfallmed Schmerzther. 2009 Jan;44(1):14-20. Epub 2008 Dec 29.

8. Buylaert WA. Coma induced by intoxication. Acta Neurol Belg. 2000 Dec;100(4):221-4.

9. Benbadis SR, Sila CA, Cristea RL. Mental status changes and stroke. J Gen Intern Med. 1994 Sep;9(9):485-7.

10. McLaren AJ, Lear J, Daniels RG. Collapse in an accident and emergency department. J R Soc Med. 1994 Mar;87(3):138-9.

11. Forsberg S, Höjer J, Enander C, Ludwigs U. Coma and impaired consciousness in the emergency room: characteristics of poisoning versus other causes. Emerg Med J. 2009 Feb;26(2):100-2. 